\title{
Abdominal obesity and other cardiometabolic risk biomarkers in two urban population groups with a common African heritage: Cotonou (Benin) and Port-au- Prince (Haiti)
}

\author{
Asma EL Mabchour ${ }^{1}$, Hélène Delisle ${ }^{*}$, Colette Vilgrain², Philippe Larco ${ }^{2}$, Roger Sodjinou ${ }^{3}$ and Malek Batal ${ }^{1}$ \\ ${ }^{1}$ TRANSNUT, WHO Collaborating Centre on Nutrition Changes and Development, Department of Nutrition, University of Montreal, PO Box 6128 Downtown \\ Station, Montreal H3C 3J7, Quebec, Canada \\ ${ }^{2}$ Haitian Foundation for Diabetes and Cardiovascular Diseases (FHADIMAC), 208 Lalue - P.O. Box 48 - Port-au-Prince, Haiti \\ ${ }^{3}$ West African Health Organization (WAHO), Bobo-Dioulasso, Burkina Faso
}

\begin{abstract}
The prevalence of non-communicable diseases (NCD) including obesity, diabetes and cardiovascular diseases is increasing in low and middle-income countries. Our purpose was to assess cardiometabolic risk (CMR) and the relationship between abdominal obesity (AO) and other CMR biomarkers in two urban population groups with a common African heritage but living in widely different settings, Cotonou (Benin, West Africa) and Port-au-Prince (Haiti).

The cross-sectional study included 452 apparently healthy men and women from Cotonou and Port-au-Prince (PAP) aged 25y to $60 \mathrm{y}$ and selected by cluster random sampling. We used the definition of the International Diabetes Federation for the metabolic syndrome (MetS) including the generic waist circumference cut-offs. Insulin resistance was set at the $75^{\text {th }}$ centile of Homeostasis Model Assessment (HOMA-IR) for the whole sample of subjects. High atherogenicity index (total serum cholesterol/HDL-Cholesterol $>4$ in men, $>5$ in women) and inflammation according to high-sensitivity C-reactive protein (hsCRP) were also assessed.

MetS prevalence was $21.5 \%$ and $16.1 \%$ in Cotonou and PAP, respectively. The most prevalent MetS components were low HDL-cholesterol, followed by AO and high blood pressure. AO was much higher in women than in men: $83 \%$ vs. $22 \%$ in Cotonou, and $67 \%$ vs. $9.6 \%$ in PAP. Insulin resistance and high atherogenicity index were roughly twice as prevalent in PAP as in Cotonou in spite of a lower AO prevalence in the former setting. High hsCRP was not significantly different (20.3\% in Cotonou, $13.6 \%$ in PAP). Controlling for age and city, AO was independently associated with CMR biomarkers except for hyperglycemia and the association was much stronger in men than in women.
\end{abstract}

Although CMR was high in both settings, differential rates were noted for specific biomarkers; environmental determinants need to be investigated. Ethno-specific $\mathrm{WC}$ cut-offs for $\mathrm{AO}$ are needed particularly for women.

\section{Introduction}

Abdominal obesity $(\mathrm{AO})$ has been gradually recognized as a metabolic disorder that contributes more to the cardiometabolic risk (CMR) than general obesity as defined by highbody mass index (BMI) $[1,2]$. It is associated with dysglycemia, dyslipidemia, insulin resistance, subclinical inflammation and hypertension $[3,4]$. Whilemany studies have established the relationship between $\mathrm{AO}$ and other CMR biomarkers in Caucasians, there is still a dearthof such data for African and African-origin populations $[5,6]$. These population groups, whether in sub-Saharan Africa or the Caribbean, are currently undergoing the nutrition transition, with shifts toward atherogenic diets and sedentary lifestyles along with increased urbanization, all factors that increase obesity and its related metabolic disorders $[7,8]$.

Owing to the absence of specific waist circumference (WC) cutoffs, AO is defined in blacks using the generic WC cut-off values primarily determined in Europeans $[9,10]$. This results in inconsistent relationships between $\mathrm{AO}$ and other CMR biomarkers in Blacks and itcould partially explain the apparent paradox that Black populations are reportedly more likely to have obesity, hypertension, diabetes, MetS and elevated subclinical inflammation even if they have less visceral adipose tissue thanCaucasians counterparts for a given BMI or WC [11-14].

The international study conducted in Benin and in Haiti was intended to isolate the environmental and behavioural determinants of CMR as these population groups are close genetically while they

Correspondence to: Hélène Delisle, Professor Hélène Delisle, TRANSNUT, WHO Collaborating Centre on Nutrition Changes and Development, Department of Nutrition, University of Montreal, PO Box 6128 Downtown Station, Montreal H3C 3J7, Quebec, Canada; Tel : +1 514 343-6111 poste 25219, E-mail: helene.delisle@umontreal.ca

Key words: abdominal obesity, Africans, cardiometabolic risk biomarkers, metabolic syndrome

Received: September 18, 2015; Accepted: October 05, 2015; Published: October 08,2015 
Mabchour AEL (2015) Abdominal obesity and other cardiometabolic risk biomarkers in two urban population groups with a common African heritage: Cotonou (Benin) and Port-au-Prince (Haiti)

live in widely different environments. For this first paper comparing adults living in Cotonou (Benin) and Port-au-Prince (PAP, Haiti), our purpose was to assessthe prevalence of the MetS, its individual components and other CMR biomarkers (general obesity, insulin resistance, high atherogenicity index and subclinical inflammation), as well as the association of AO (according to generic WC cut-offs) with the other CMR biomarkers.

\section{Subjects and methods}

\section{Population samples and data collection}

The cross-sectional study included 452 apparently healthy subjects: 200 (100 men, 100 women) in Cotonou, the economic capital and the largest city of Benin (West Africa)with a population of 665,100 in 2002 [15]; and 252 (135 men, 117 women) in the metropolitan area of Port-au-Prince (PAP), Haiti capital with a population of 2 million according to the last census of 2003 [16]. The sample size in both areas was adequate to perform multivariate analyzes with 20 independent variables to detect small size effects with a statistical power of $80 \%$ and a confidence interval of $95 \%$ [17]. The selected age range was 25 - 60 years, as the occurrence of CMR may rapidly increase beyond age 60 , while it is usually low under the age of 25 years [18]. The selected subjects had to have lived in the study area for at least six months prior to the survey so that no changes in their lifestyle or socioeconomic status could be ascribed to their recent urban migration. Pregnant and lactating womenand subjects with diagnosed high blood pressure, diabetes or any heart condition were excluded from the study. Subjects were selected by cluster random sampling. The study was conducted in Cotonou between 2005 and 2006 and in PAP between 2008 and 2009 (Figure 1). Details of the sampling method in Cotonou were published elsewhere [19]. In PAP, themetropolitan area includes 1900 enumeration areas (EA) witheach one comprising approximately 225 households. An initial 200 EA were selected by systematic samplingand then 20 EA wererandomly selected. For each EA, 13 households were

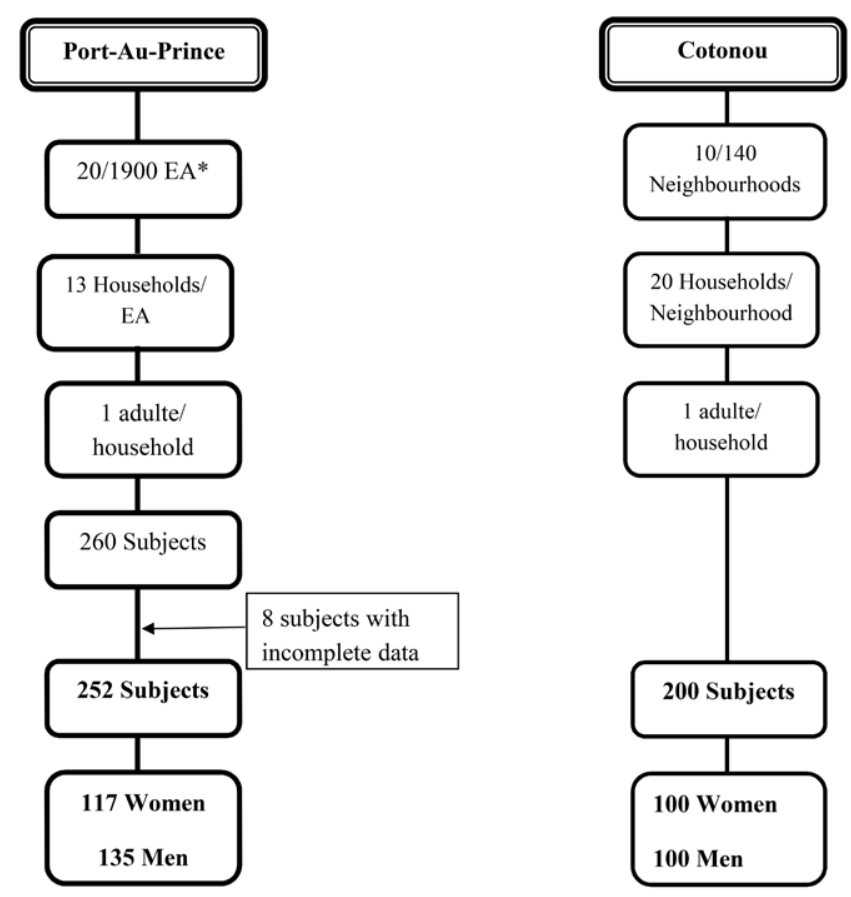

Figure 1. Cluster random sampling in PAP and in Cotonou. EA: Enumeration area randomly selected and one adult per household was retained, giving a total of 260 subjects. Eight subjects were excluded because of doubtful reliability of data, which gave a final sample of 252 subjects in PAP.

\section{Study variables and their measurement}

Methods for anthropometric and blood pressure measurements, as well as for subjects' selection andblood sampling,were standardized across sitesbefore data collection began. All biochemical analyzeswere performed in the same laboratory using the same analytical procedures in order to allowfor comparisons of the CMR biomarkers between Cotonou and PAP.

Weights and heights were measured to calculate body mass index (BMI)as a measure of general obesity. A standardized protocolwas used as defined elsewhere [19]. The World Health Organization cut-off value was used to define general obesity $\left(\mathrm{BMI} \geq 30 \mathrm{~kg} / \mathrm{m}^{2}\right)$ [20]. Abdominal obesitywas defined according to the International Diabetes Federation (IDF) generic WC criteria in the absence of ethno-specific data(WC $\geq 94 \mathrm{~cm}$ in men, $\geq 80 \mathrm{~cm}$ in women) [10]. WC was measured using a flexible non-stretch tape to the nearest $0.1 \mathrm{~cm}$ at midpoint between the lower rib and the iliac crest while subjects were standing and breathing normally. The average of two measures of WC was used in the analyzes [21].

Blood pressurewasmeasured using a mercury sphygmomanometer. Two readings of systolic (SBP) and diastolic blood pressure (DBP) were taken on the right arm of each subject in a sitting position after a 10 minute rest.The time interval between two consecutive measures was at least 10 minutes. The mean value of two readings of SBP andDBP was used in analyses. High blood pressure was defined as $\mathrm{SBP} \geq 130$ $\mathrm{mmHg}$ or DBP $\geq 85 \mathrm{mmHg}$ [10].

Venous blood samples $(10 \mathrm{ml})$ were drawn after an over-night fast of 12 hours and were centrifuged within two hours [19]. Plasma samples were stored at $-20^{\circ} \mathrm{C}$ in each site and shipped in dryice to the Biochemical laboratory of the UniversityHospital of Nancy (France) for biochemical analysis. High-sensitivity C-reactive protein (hsCRP) was assessed by immunonephelometry andhigh risk subclinical inflammation was present when hsCRP concentration was between 3 and $10 \mathrm{mg} / \mathrm{L}$ [22]. Serum insulin was measured by radioimmunoassay and insulin resistancecut-off was the $75^{\text {th }}$ centile (3.9) of the calculatedHomeostasis Model Assessment index (HOMA-IR) [(fasting glucose $\mathrm{x}$ fasting insulin)/22.5] for all study subjects [23]. Plasma glucose was measured by a glucose oxidase method and fasting hyperglycemia was defined asglucose concentration $\geq 5.6 \mathrm{mmol} / \mathrm{L}$ [10]. Serum total cholesterol (TC), HDL cholesterol (HDL-C) and triglycerides (TG) were measured by enzymatic colorimetric method. Low HDL-Ccutoff values were $<1.03 \mathrm{mmol} / \mathrm{L}$ in men and $<1.29 \mathrm{mmol} / \mathrm{L}$ in women. Hypertriglyceridemia was defined byTG concentrations $\geq 1.7 \mathrm{mmol} / \mathrm{L}$ [24]. The atherogenicity index (TC/HDL-C) was considered at risk when $>5$ in men and $>4$ in women [25].

The metabolic syndrome (MetS) was defined according to the last joint interim statement of several organizations, and was present when any three of the following five components were present: $\mathrm{AO}$, high blood pressure, elevated fasting glucose, elevated triglycerides, and low HDL-C [10].

\section{Statistical analysis}

Data were processed and analyzed with SPSS (version 21.0, Chicago Inc.). Means, standard deviations, medians and centiles were calculated for continuous variables, and UMann-Whitney test or t-test wereused 
Mabchour AEL (2015) Abdominal obesity and other cardiometabolic risk biomarkers in two urban population groups with a common African heritage: Cotonou (Benin) and Port-au-Prince (Haiti)

when appropriate to compare data between Cotonou and PAP and between women and men. Comparisons of CMR biomarkers between the two groups in men and in women used the $\chi^{2}$ test for categorical data.Multiple logistic regression analyses were performed to assess the independent association ofAOwitheach of the other CMRbiomarkers in men and in women,adjusting for age and city.Statistical significance was setat $\mathrm{p}<0.05$.

\section{Ethical considerations}

The initial studies were approved by the Ethics and Health Research Committees of the Faculty of Medicine,University of Montreal, the Ministry of Public Health and Population of Haiti and the Ministry of Healthin Benin. All participants signed an informed consent form. The subjects in whomhypertension or dysglycemiawas detected in the course of the study were referred to a physician for diagnosis and the first consultation was covered by project funds. The study results were fed back to Benin and Haiti.

\section{Results}

\section{Study subjects' characteristics}

Characteristics of the study subjects $(n=452)$ by sex and according to the studyarea are shown in Table 1 . For subclinical inflammation analyses, $6.5 \%(n=13)$ of Beninese and 9.5\% $(n=24)$ of Haitians with plasmahsCRP concentration above $10 \mathrm{mg} / \mathrm{L}$ were excluded because of likelyinfection. The mean age of subjects was under 40 years for men and women in both locations and it was not significantly different between Cotonou and PAP within sex groups. WC, BMI, SBP, HDLCandhsCRPconcentrationsweresignificantly higher in Cotonou than in PAP, in both men and women. Conversely, DBP, TG concentration, TC/HDL-C ratio and HOMA-IR index were significantly higher in PAP than in Cotonou in both men and women. Fasting plasma glucose was not significantly different between the two cities in either men and women.

\section{Prevalence of MetSand its individual components}

MetS was present in $21.5 \%$ and $16.1 \%$ of subjects in Cotonouand PAP, respectively (Figure 2), with no significant difference. Low HDL-C was the most prevalent MetS component in both groups, affecting more than $75 \%$ of subjects andsignificantly higher in PAP than in Cotonou. $\mathrm{AO}$ was significantly more prevalent in Cotonouwhere more than half the subjects were affected.High blood pressure was present in one out of four or five subjects, with no significant difference between the two cities. The MetS was present in $28.2 \%$ of women versus $14.9 \%$ of men $(p<0.001)$. As can be seen in Figure 3, MetS individual components were all much more prevalent in women than men, except for fasting hyperglycemia. Overall, $75 \%$ of women had central obesity compared toless than $15 \%$ of men $(\mathrm{p}<0.001)$. High blood pressure was present in more than $25 \%$ of women and $20 \%$ of men $(p=0.034)$. Low HDL-C was present in $94 \%$ of women and in $76.6 \%$ of men $(p<0.001)$. In Cotonou as well as PAP, the prevalence of the MetS was three to five times higher and that of $\mathrm{AO}$ was four to six times higher in women than men (Figure 3). AO prevalence was significantly higher in Cotonou than in PAP in both men ( $\mathrm{p}=0.008)$ and women ( $\mathrm{p}=0.012$ in women), while HDL-C was significantly higher in PAP than in Cotonou but only in men $(p=0.008)$. Fasting hyperglycemia was uncommon and was not significantly different between cities, in men and in women. Hypertriglyceridemia was not observed in Cotonou and was present in only $2.2 \%(n=3)$ of men in PAP.

\section{Prevalence of other CMR biomarkers}

High atherogenicity index (TC/HDL-C) and insulin resistance were both much higher and significantly so in PAP than in Cotonou. General obesity was present in one out of five subjects and one out of six, respectively, in Cotonou and in PAP, with no significant difference between cities. Subclinical inflammation was present in about $20 \%$ of subjects in each city, and its prevalence was not significantly different (Figure 4). Much like for the prevalence of the MetS and its components

Table 1. Anthropometrical and biological data of subjects by sex and according to cities.

\begin{tabular}{|c|c|c|c|c|c|c|}
\hline & \multicolumn{3}{|c|}{ Women $(n=217)$} & \multicolumn{3}{|c|}{$\operatorname{Men}(n=235)$} \\
\hline & $\begin{array}{l}\text { Cotonou } \\
(n=100)\end{array}$ & $\begin{array}{c}\text { PAP } \\
(n=117)\end{array}$ & $\mathbf{p}$ & $\begin{array}{l}\text { Cotonou } \\
(n=100)\end{array}$ & $\begin{array}{c}\text { PAP } \\
(n=135)\end{array}$ & $\mathbf{p}$ \\
\hline Age(years) & $40.0 \pm 9.6$ & $38.2 \pm 10.1$ & 0.186 & $37.8 \pm 9.8$ & $35.7 \pm 10.4$ & 0.114 \\
\hline WC (cm) & $91.1 \pm 13.1$ & $86.4 \pm 13.6$ & 0.010 & $84.4 \pm 12.7$ & $79.6 \pm 11.6$ & 0.003 \\
\hline BMI $\left(\mathrm{Kg} / \mathrm{m}^{2}\right)^{*}$ & $\begin{array}{c}28.1 \pm 5.827 .9 \\
(23.4-30.7)\end{array}$ & $\begin{array}{c}25.8 \pm 5.824 .9 \\
(21.8-28.7)\end{array}$ & 0.004 & $\begin{array}{c}23.4 \pm 4.422 .5 \\
(20.3-25.7)\end{array}$ & $\begin{array}{c}22.2 \pm 5.221 .1 \\
(18.8-24.2)\end{array}$ & 0.011 \\
\hline SBP (mmHg) & $\begin{array}{c}126.9 \pm 24.0120 .0 \\
(110-138.6)\end{array}$ & $\begin{array}{c}120.2 \pm 22.2120 .0 \\
(105.0-130.0)\end{array}$ & 0.029 & $\begin{array}{c}121.9 \pm 19.0120 .0 \\
(110.0-130.0)\end{array}$ & $\begin{array}{c}114.0 \pm 15.9110 .0 \\
(100.0-120.0)\end{array}$ & 0.001 \\
\hline DBP (mmHg) & $75.5 \pm 13.8$ & $79.6 \pm 14.0$ & 0.033 & $72.0 \pm 11.7$ & $75.4 \pm 11.3$ & 0.027 \\
\hline TG $(\mathrm{mmol} / \mathrm{L})$ & $0.7 \pm 0.2$ & $0.8 \pm 0.3$ & $<0.001$ & $0.7 \pm 0.2$ & $0.8 \pm 0.3$ & 0.004 \\
\hline HDL-C (mmol/L) & $1.0 \pm 0.2$ & $0.6 \pm 0.3$ & $<0.001$ & $1.0 \pm 0.2$ & $0.7 \pm 0.3$ & $<0.001$ \\
\hline TC/HDL-C ${ }^{*}$ & $\begin{array}{c}4.3 \pm 1.14 .3 \\
(3.5-5.0)\end{array}$ & $\begin{array}{c}7.4 \pm 3.56 .7 \\
(4.9-8.8)\end{array}$ & $<0.001$ & $\begin{array}{c}4.3 \pm 1.23 .9 \\
(3.5-5.1)\end{array}$ & $\begin{array}{c}6.1 \pm 2.55 .6 \\
(4.2-7.2)\end{array}$ & $<0.001$ \\
\hline FPG $(\mathbf{m m o l} / \mathbf{L})^{*}$ & $4.6 \pm 0.6$ & $\begin{array}{c}4.6 \pm 0.94 .6 \\
(4.1-5.1)\end{array}$ & 0.824 & $\begin{array}{c}4.6 \pm 0.74 .5 \\
(4.3-4.8)\end{array}$ & $\begin{array}{c}4.7 \pm 1.34 .6 \\
(4.1-5.1)\end{array}$ & 0.884 \\
\hline hsCRP (mg/L)" & $\begin{array}{c}2.8 \pm 2.52 .1 \\
(0.9-4.0)\end{array}$ & $\begin{array}{c}1.8 \pm 2.50 .7 \\
(0.3-2.5)\end{array}$ & $<0.001$ & $\begin{array}{c}1.5 \pm 1.70 .9 \\
(0.6-1.8)\end{array}$ & $\begin{array}{c}1.2 \pm 1.80 .4 \\
(0.2-1.2)\end{array}$ & $<0.001$ \\
\hline HOMA-IR $^{*}$ & $\begin{array}{c}2.7 \pm 1.82 .0 \\
(1.3-3.8)\end{array}$ & $\begin{array}{c}3.8 \pm 2.03 .3 \\
(2.5-4.6)\end{array}$ & $<0.001$ & $\begin{array}{c}2.0 \pm 1.51 .4 \\
(1.0-2.6)\end{array}$ & $\begin{array}{c}3.3 \pm 1.72 .9 \\
(2.2-4.0)\end{array}$ & $<0.001$ \\
\hline
\end{tabular}

PAP: Port-au-Prince; WC: Waist circumference; BMI: Body mass index; SBP: Systolic blood pressure; DBP: Diastolic blood pressure; hsCRP: High sensitivity C-reactive protein; HOMAIR: Homeostatic model assessment-Insulin resistance; FPG: Fasting plasma glucose; TG: Triglycerides; HDL-C: High density lipoprotein- cholesterol; TC/HDL-C: Total cholesterol/HDL-C ratio. Data expressed by mean value \pm Standard deviation. " $:$ data expressed by mean value \pm Standard deviation and median $\left(25^{\text {th }}-75^{\text {th }}\right.$ centiles $)$ 


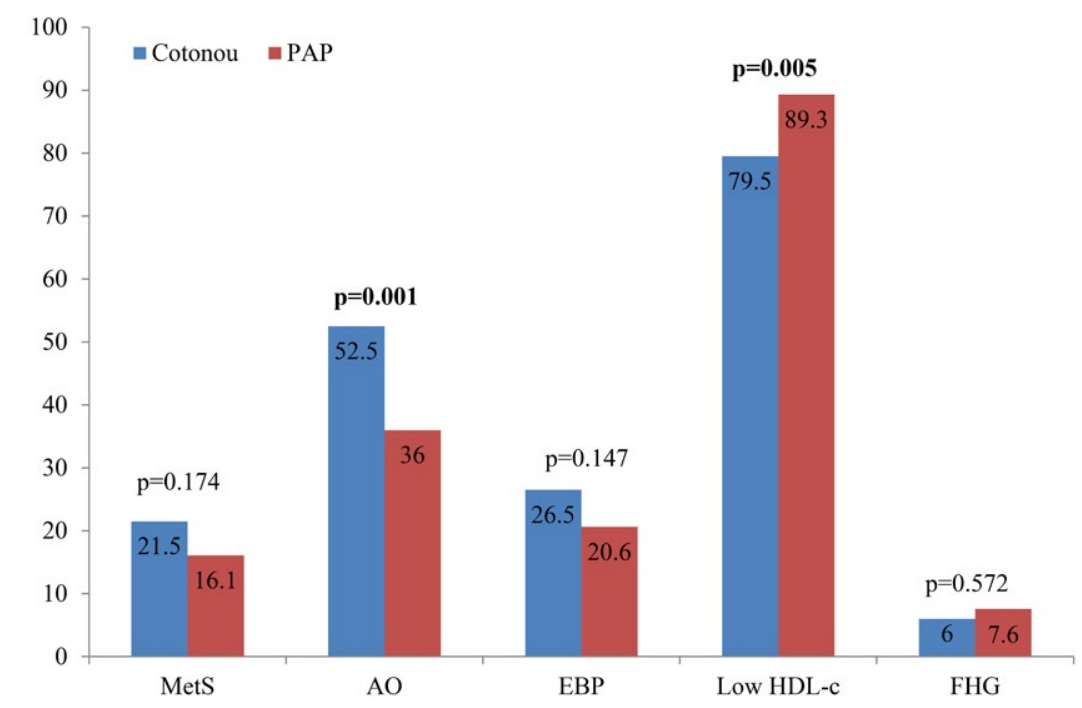

Figure 2. Prevalence of the metabolic syndrome and its individual components in Cotonou and in Port-au-Prince. PAP; Port-au-Prince; MetS: Metabolic Syndrome; AO: Abdominal obesity; HDL-C: High density lipoprotein-cholesterol; FHG: Fasting hyperglycemia. p: for $\chi 2$ test significant at $\mathrm{p}<0.005$. Prevalence values are in percentages.

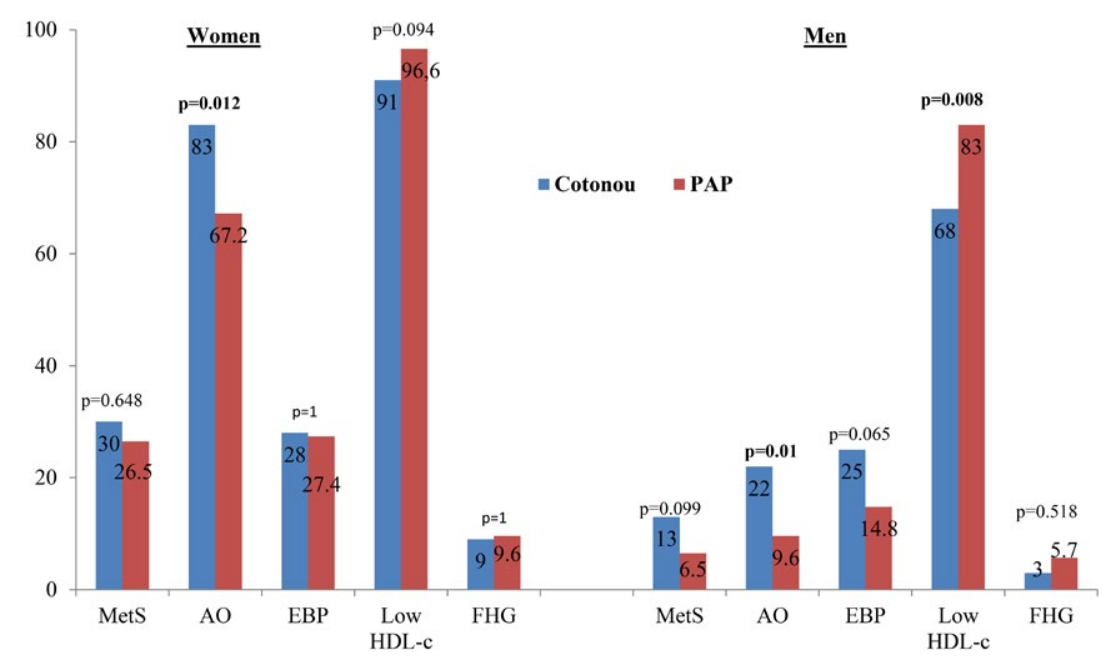

Figure 3. Prevalence of the metabolic syndrome and its individual components in women and men.PAP; Port-au-Prince; MetS: Metabolic Syndrome; AO: Abdominal obesity; HDL-C: High density lipoprotein-cholesterol; FHG: Fasting hyperglycemia. $\mathrm{p}$ : for $\chi 2$ test significant at $\mathrm{p}<0.005$. Prevalence values are in percentages.

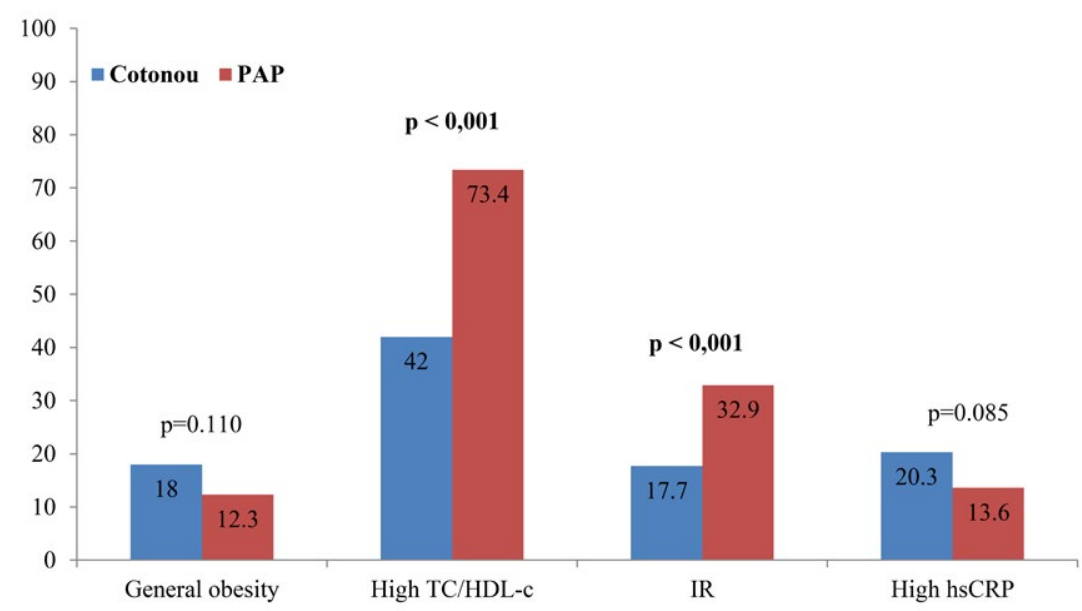

Figure 4. Prevalence of other CMR biomarkers in Cotonou and in Port-au-Prince. PAP: Port-au-Prince; CT/HDL-C: Total cholesterol/HDL-C ratio; IR: Insulin resistance; hsCRP: high sensitivity C-reactive protein; $\mathrm{p}$ : for $\chi 2$ test, significant at $\mathrm{p}<0.005$. Prevalence values are in percentages. 
Mabchour AEL (2015) Abdominal obesity and other cardiometabolic risk biomarkers in two urban population groups with a common African heritage: Cotonou (Benin) and Port-au-Prince (Haiti)

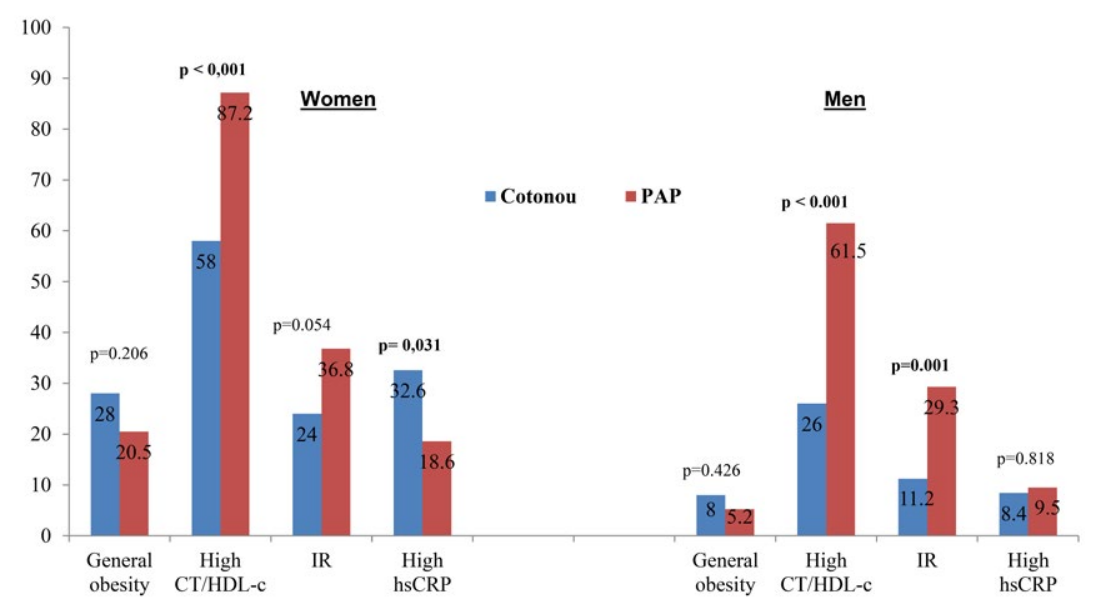

Figure 5. Prevalence of other CMR biomarkers in women and men. PAP: Port-au-Prince; CT/HDL-C: Total cholesterol/HDL-C ratio; IR: Insulin resistance; hsCRP: high sensitivity $\mathrm{C}$-reactive protein; $\mathrm{p}$ : for $\chi 2$ test significant at $\mathrm{p}<0.005$. Prevalence values are in percentages.

(Figure 3), women had a significantly more altered metabolic profile than men. There were four times more women than men with general obesity $(24.0 \%$ vs $6.4 \% ; \mathrm{p}<0.001) ; 25.3 \%$ of women had subclinical inflammation compared with $9.0 \%$ of men $(\mathrm{p}<0.001)$; and a high atherogenicity index was observed in $75 \%$ of women compared with $50 \%$ of men $(\mathrm{p}<0.001)$. Comparing these CMR biomarkers by city and sex, a high atherogenicity index and insulin resistance were significantly more prevalent in PAP than in Cotonou in both men and women. Subclinical inflammation was significantly higher in Cotonou but only in women, while insulin resistance was more highly prevalent in PAP than in Cotonou but only in men (Figure 5).

\section{Relationship between abdominal obesity and otherCMR biomarkers}

In multiplelogistic regression models adjusted for age and city, AO (according to generic WC cut-off values)was associated with significantly higher odds of high blood pressure, high atherogenicity index, and insulin resistance in both men and women.AO increased the odds of subclinical inflammation only in women and of low HDL-C only in men while no significant association was found with hyperglycemia. AO was much more predictive of most of the other CMR biomarkers in men than in women. (Table 2).

\section{Discussion}

In two apparently healthy groups of subjects with a common African heritage, we found a high prevalence of several components of the MetS and other CMR biomarkers, namely subclinical inflammation, insulin resistance and a high atherogenicity index. We observed that $\mathrm{AO}$ was much higher in Cotonou than in PAP, and paradoxically, that the atherogenic profile and insulin resistance were higher in PAP than in Cotonou. We also found that $\mathrm{AO}$ according to generic WC cut-off values was more closely associated with other CMR biomarkers in men than in women.

The observed prevalence of the MetS according to the most recent criteria (16\% in PAP, $21.5 \%$ in Cotonou) is in line with the $23.5 \%$ prevalence reported in black rural South Africans using the same criteria [26]. Surprisingly, the reported prevalence in Haitians living in Montreal (17.5\%) fell inbetween the observed rates in Cotonou and
Table 2. Association of abdominal obesity with other CMR biomarkers in women and in men.

\begin{tabular}{|l|c|c|c|c|}
\hline \multirow{2}{*}{} & \multicolumn{2}{|c|}{ Women } & \multicolumn{2}{c|}{ Men } \\
\cline { 2 - 5 } & OR*(95\% CI) & p & OR (95\% CI) & p \\
\hline High blood pressure & $5.1(1.86-13.84)$ & 0.002 & $6.1(2.46-14.95)$ & $<0.001$ \\
\hline Low HDL-C & $1.7(0.48-10.6)$ & 0.421 & $7.2(1.62-32.32)$ & 0.010 \\
\hline High hsCRP & $5.1(1.70-15.07)$ & 0.004 & $1.8(0.69-4.71)$ & 0.229 \\
\hline Insulin resistance & $2.9(1.33-6.27)$ & 0.007 & $6.3(2.50-16.32)$ & $<0.001$ \\
\hline
\end{tabular}

OR: Odds Ratio; PAP: Port-au-Prince; hsCRP: high sensitivity C-reactive protein; CT/ HDL-C: Total cholesterol/HDL-C ratio.

*: Multiple logistic regressions. OR adjusted for city and age

PAP [27]. We would have expected an upward gradient from Benin to Haiti to Canada [28]. Similar prevalence figures were also reported in other groups of African descent, for instance in Jamaica, where the rate was $10.6 \%$ in men and $27.6 \%$ in women [29], compared with $26.5 \%$ $30 \%$ in women of our study and $6.5 \%-13 \%$ in men. A much higher rate was reported in the Jackson Heart Study among African-Americans, with a prevalence of $39.4 \%$ according to the definition of NCEP/ATPIII (National Cholesterol Evaluation Program - Adult Treatment Panel) [12]. However, the subjects were much older than in our study, with a mean age of 54y compared with 40y. Otherwise, widely divergent MetS prevalence rates have been reported, ranging from less than $2 \%$ in urban Cameroonians in 2007[30] to more than 50\% in a community of Congo in 2013[31]. This heterogeneity of the data on MetS prevalence even in black populations reflects not only true disparities owing to different geographic, economic and lifestyle factors, but also the lack of a unified definition of the MetS up to recently[5, 9, 10, 32]. It also betrays the paucity of epidemiological data on MetS and its components in Africans as most studies have been conducted among African Americans [11,12,33]

Regarding individual MetS components, we observed that the two study groups had similar prominent features: central obesity, low HDL-C and high blood pressure, but not hypertriglyceridemia. Our results corroborate other findings on the MetS profile in Africanorigin populations, compared with Caucasians and other ethnic 
groups where hypertriglyceridemia is a major MetS component $[9,12,26,27,34]$. Normal TG concentrations in Blacks in the presence of insulin resistance and low HDL-CHDL-C is often called the lipid paradox' or more specifically the 'TG paradox' [35,36]. As observed by Sumner et al. [35], there is apparently no effect of insulin resistance on postheparin-lipoprotein lipase activity in insulin resistant AfricanAmericans, whereas in other ethnic groups, the lipoprotein lipase activity is usually impaired when circulating TG are elevated as a result of insulin resistance. Lipoprotein lipase appears to be allowed to clear triglycerides even in the presence of insulin resistance, which could explain the coexistence of insulin resistance and normal triglyceridemia in black Africans.

Low HDL-C was the most prevalent MetS component in the present study and it was widespread: $79.5 \%$ in Cotonou and $89.3 \%$ in PAP. In accordance with our results, Sumner et al. [37] demonstrated that even in normal weight subjects of West African cities, HDL-C levels were below the cut-off point. The study reported more than $80 \%$ of low HDL-C in West Africans and African-Americans. In a previous report on Benin subjects, HDL-C tended to be low at both ends of the BMI spectrum [38]. Overall, a decrease of HDL-C level has apparently occurred in Africa in the last four decades because of urbanization and lifestyle changes $[12,37]$. The high prevalence of low HDL-C in our study, if not related to deterioration of serum samples during storage, has to be taken seriously because of the cardioprotective properties of HDL-Cal though these are challenged at the present time and may be altered in certain conditions [39]. Hypertension is widely prevalent in Black population groups $[12,40]$. Our results confirmed this as well as the independent association of high blood pressure with $\mathrm{AO}[41,42]$.

A high prevalence of elevated TC/HDL-C ratio was also observed in our study. This ratio has been regarded as a better predictor of cardiovascular risk than elevated TG concentrations even in Caucasians $[43,44]$. Our findings suggest that this ratio may be even more useful as predictor of the CMR in black populations where hypertriglyceridemia is uncommon.

High sensitivity CRP as marker of subclinical inflammation adds clinically useful prognostic information to the MetS [45]. In the present study, subclinical inflammation was present in roughly $20 \%$ of subjects without significant differences between the sites except for a significantly higher rate in Cotonou than PAP women. This significant difference in women but not in men is likely a reflection of the much higher rate of $\mathrm{AO}$ in women. Subclinical inflammation is described as the link between obesity, more specifically $\mathrm{AO}$, insulin resistance and related metabolic disorders [46,47]. Race/ethnicity studies reported higher subclinical inflammation in women than men, and in African-Americans than Caucasians [48]. Among non-Hispanic Americans, hsCRP levels were twice as high in subjects with general or abdominal obesity [49]. For similar BMI and WC, African-Americans especially women showed higher inflammatory marker values than other ethnic groups in spite of lower visceral adipose tissue, but subclinical inflammation was found to be more closely associated with subcutaneous than visceral adipose tissue $[33,48]$.

In both cities, women had much more obesity than men. Other studies in low-and middle-income countries of Africa have highlighted this disparity between men and women [19,50]. Differences in physical activity in urban areas and the positive image of women's obesity as a sign of beauty and opulence in many African cultures, along with multiparity, could explain the higher prevalence of obesity, whether general or abdominal, among women [50,51].
Even if $\mathrm{AO}$ was much higher in Cotonou than PAP, insulin resistance, low HDL-C and high atherogenicity index were more prevalent in PAP, while there was no significant difference between cities in the occurrence of the MetS, general obesity, subclinical inflammation and hyperglycemia. These results are partially at variance with the ten-fold positive gradient reported for obesity, high blood pressure, insulin resistance, inflammation and diabetes from West Africa to the Caribbean and to the United States or the United Kingdom [28,52,53]. These outcome differentials were ascribed primarily to shifting lifestyles and diets when moving to a new environment. Along these lines, the CMR profile may be more altered in Haiti than in Benin because of the geographical proximity to the United States with more potential exposure to Western lifestyle and highly processed foods. Obviously, the nutrition transition is a more complex phenomenon than previously implied in the African diaspora studies [28,52]. Analyses of available lifestyle and socioeconomic data will be useful to explain the observed discrepancies between Cotonou and PAP subjects. Notwithstanding, we would have expected AO and the other CMR markers to move in the same direction which was not the case. Additionally, the prevalence of $\mathrm{AO}$ as empirically defined based on generic WC cut-offs was at least three times as high in women as in men, and therefore, we would have expected the other CMR biomarkers to be considerably higher in women than men. However, this was not observed and actually, there was a tighter association of $\mathrm{AO}$ with other CMR biomarkers in men than in women. We may therefore suspect, like others did [26], that the generic WC cut-offs for $\mathrm{AO}$ are not appropriate for black subjects, particularly for women. Studies in South Africa suggested a lower WC cut-off for AO in men and a higher one in women ( $\geq 86 \mathrm{~cm}$ in $\mathrm{men} ; \geq 92 \mathrm{~cm}$ in women) based on predictive value of at least two MetS components [26]. Further work on anthropometric indicators of $\mathrm{AO}$ is obviously required in Africans.

To the best of our knowledge, this is the first study comparing the association of AO with other CMR biomarkers in two populations of African origin but living in different environments: Benin and Haiti. However, the cross-sectional study design prevents any inference as to a cause-effect relationship of $\mathrm{AO}$ with the other CMR biomarkers.

\section{Conclusion}

In two groups of apparently healthy city dwellers with a common African heritage but living in widely different settings (West Africa; Caribbean), cardiometabolic risk was highly prevalent, which calls for preventive action. AO, as defined with WC generic cut-off values, was much more prevalent in women than men, but it was more closely associated with other CMR biomarkersin men. Specific cut-off points would be required for blacks, particularly for women, which warrants further research.

\section{Authorship and contributorship}

HD is the principal investigator in charge of the Nutrition Transition Multicenter Study. She designed the study and developed the initial protocol with RS, CV and PL. RS refined the protocol for Cotonou, collected the data in the field and performed data analyses other than those reported in this paper. CV and PL supervised the data collection in PAP and were involved in manuscript revision. AEM did the data cleaning for PAP, she conducted the statistical analyses, she participated in the feedback of study results in Haiti and she drafted the manuscript under HD supervision. MB participated in the feedback of study results in Haiti and thoroughly revised and corrected the manuscript. 
Mabchour AEL (2015) Abdominal obesity and other cardiometabolic risk biomarkers in two urban population groups with a common African heritage: Cotonou (Benin) and Port-au-Prince (Haiti)

\section{Acknowledgments}

We thank Dr JL Guéant, University Henry Poincaré (Nancy, France) for biochemical analyzes.

\section{Funding information}

Canadian Institute for Health Research (CIHR), Canada. Grant no FRN68892 Author: HD The funding agency had not any role in study design, data collection and analysis, decision to publish or preparation of the manuscript.

\section{Competing interest}

The authors declare that they have no competing interests.

\section{References}

1. Yusuf S, Hawken S, Ounpuu S, Bautista L, Franzosi MG, et al. (2005) Obesity and the risk of myocardial infarction in 27,000 participants from 52 countries: a case-control study. Lancet 366: 1640-1649. [Crossref]

2. Zhu S, Wang Z, Heshka S, Heo M, Faith MS, et al. (2002) Waist circumference and obesity-associated risk factors among whites in the third National Health and Nutrition Examination Survey: clinical action thresholds. Am J Clin Nutr 76: 743-749. [Crossref]

3. Després JP (2012) Body fat distribution and risk of cardiovascular disease: an update. Circulation 126: 1301-1313. [Crossref]

4. Chan JM, Rimm EB, Colditz GA, Stampfer MJ, Willett WC (1994) Obesity, fat distribution, and weight gain as risk factors for clinical diabetes in men. Diabetes Care 17: 961-969. [Crossref]

5. Dalal S, Beunza JJ, Volmink J, Adebamowo C, Bajunirwe F, et al. (2011) Noncommunicable diseases in sub-Saharan Africa: what we know now. Int J Epidemiol 40: 885-901. [Crossref]

6. Sossa C, Delisle H, Agueh V, Makoutodé M, Fayomi B (2012) Four-Year Trends in Cardiometabolic Risk Factors according to Baseline Abdominal Obesity Status in West-African Adults: The Benin Study. J Obes 2012: 740854. [Crossref]

7. Boutayeb A (2006) The double burden of communicable and non-communicable diseases in developing countries. Trans R Soc Trop Med Hyg 100: 191-199. [Crossref]

8. Popkin BM (2004) The nutrition transition: an overview of world patterns of change. Nutr Rev 62: S140-143. [Crossref]

9. Osei K (2010) Metabolic syndrome in blacks: are the criteria right? Curr Diab Rep 10: 199-208. [Crossref]

10. Alberti KG, Eckel RH, Grundy SM, Zimmet PZ, Cleeman JI, et al. (2009). Harmonizing the metabolic syndrome: a joint interim statement of the International Diabetes Federation Task Force on Epidemiology and Prevention; National Heart, Lung, and Blood Institute; American Heart Association; World Heart Federation; International Atherosclerosis Society; and International Association for the Study of Obesity. Circulation 120: 1640-5. [Crossref]

11. Liu J, Hickson DA, Musani SK, Talegawkar SA, Carithers TC, et al. (2013). Dietary patterns, abdominal visceral adipose tissue, and cardiometabolic risk factors in African Americans: the Jackson heart study. Obesity (Silver Spring) 21: 644-51. [Crossref]

12. Taylor H, Liu J, Wilson G, Golden SH, Crook E, et al. (2008) Distinct component profiles and high risk among African Americans with metabolic syndrome: the Jackson Heart Study. Diabetes Care 31: 1248-1253. [Crossref]

13. Hyatt TC, Phadke RP, Hunter GR, Bush NC, Muñoz AJ, et al. (2009) Insulin sensitivity in African-American and white women: association with inflammation. Obesity (Silver Spring) 17: 276-282. [Crossref]

14. Désilets MC, Garrel D, Couillard C, Tremblay A, Després JP, et al. (2006) Ethnic differences in body composition and other markers of cardiovascular disease risk: study in matched Haitian and White subjects from Quebec. Obesity (Silver Spring) 14: 10191027. [Crossref]

15. Institut National de la Statistique et de l'Analyse Economique (INSAE) (2003) Troisième recensement général de la population et de l'habitation 2002 : Synthèse des résultats, INSEA

16. Institut Haïtien de Statistique et de l'Informatique (IHSI). IVe recensement général de la population et de l'habitat de 2003, IHSI.
17. Cohen J 1988. Statistical power analysis for the behavioural (2nd ed), New Jersey, Lawrence Erlbaum Associates.

18. Tostain J, Heim M, Rossi D (2004) Action of androgens on fat distribution and metabolic balance. Prog Urol 14: 689-701. [Crossref]

19. Sodjinou R, Agueh V, Fayomi B, Delisle H (2008) Obesity and cardio-metabolic risk factors in urban adults of Benin: relationship with socio-economic status, urbanisation, and lifestyle patterns. BMC Public Health 8: 84. [Crossref]

20. World Health Organisation 1999. International Society of Hypertension. Guidelines for the management of hypertension. Guidelines sus commette.

21. Després JP, Lemieux I, Prud'homme D (2001) Treatment of obesity: need to focus on high risk abdominally obese patients. BMJ 322: 716-720. [Crossref]

22. Pearson TA, Mensah GA, Alexander RW, Anderson JL, Cannon RO, 3rd, et al. (2003). Markers of inflammation and cardiovascular disease: application to clinical and public health practice: A statement for healthcare professionals from the Centers for Disease Control and Prevention and the American Heart Association. Circulation 107: 499-511. [Crossref]

23. Matthews DR, Hosker JP, Rudenski AS, Naylor BA, Treacher DF, et al. (1985) Homeostasis model assessment: insulin resistance and beta-cell function from fasting plasma glucose and insulin concentrations in man. Diabetologia 28: 412-419. [Crossref]

24. Bersot TP, Pépin GM, Mahley RW (2003) Risk determination of dyslipidemia in populations characterized by low levels of high-density lipoprotein cholesterol. $\mathrm{Am}$ Heart J 146: 1052-1059. [Crossref]

25. National Cholesterol Education Program Expert Panel on Detection E, Treatmen of High Blood Cholesterol In A (2002). Third Report of the National Cholesterol Education Program (NCEP) Expert Panel on Detection, Evaluation, and Treatment of High Blood Cholesterol in Adults (Adult Treatment Panel III) final report. Circulation 106, 3143-421. [Crossref]

26. Motala AA, Esterhuizen T, Pirie FJ, Omar MA (2011) The prevalence of metabolic syndrome and determination of the optimal waist circumference cutoff points in a rural South african community. Diabetes Care 34: 1032-1037. [Crossref]

27. Delisle H, Désilets MC, Vargas ER, Garrel D (2008) Metabolic syndrome in three ethnic groups using current definitions. Appl Physiol Nutr Metab 33: 356-360. [Crossref]

28. Luke A, Cooper RS, Prewitt TE, Adeyemo AA, Forrester TE (2001) Nutritiona consequences of the African diaspora. Annu Rev Nutr 21: 47-71. [Crossref]

29. Ferguson TS, Younger N, Tulloch-Reid MK, Forrester TE, Cooper RS, et al. (2010) Prevalence of the metabolic syndrome in Jamaican adults and its relationship to income and education levels. West Indian Med J 59: 265-273. [Crossref]

30. Fezeu L, Balkau B, Kengne AP, Sobngwi E, Mbanya JC (2007) Metabolic syndrome in a sub-Saharan African setting: central obesity may be the key determinant. Atherosclerosis 193: 70-76. [Crossref]

31. Katchunga PB, Hermans M, Bamuleke BA, Katoto PC, Kabinda JM (2013) Relationship between waist circumference, visceral fat and metabolic syndrome in a Congolese community: further research is still to be undertaken. Pan Afr Med J 14, 20. [Crossref]

32. World Health Organization (2000) Title of report: Obesity: preventing and managing the global epidemic; Report of a WHO Consultation.

33. Carroll JF, Fulda KG, Chiapa AL, Rodriquez M, Phelps DR, et al. (2009) Impact of race/ethnicity on the relationship between visceral fat and inflammatory biomarkers. Obesity (Silver Spring) 17: 1420-1427. [Crossref]

34. Désilets MC, Rivard M, Shatenstein B, Delisle H (2007) Dietary transition stages based on eating patterns and diet quality among Haitians of Montreal, Canada. Public Health Nutr 10: 454-463. [Crossref]

35. Sumner AE, Vega GL, Genovese DJ, Finley KB, Bergman RN, et al. (2005) Normal triglyceride levels despite insulin resistance in African Americans: role of lipoprotein lipase. Metabolism 54: 902-909. [Crossref]

36. Yu SS1, Castillo DC, Courville AB, Sumner AE (2012) The triglyceride paradox in people of African descent. Metab Syndr Relat Disord 10: 77-82. [Crossref]

37. Sumner AE, Zhou J, Doumatey A, Imoisili OE, Amoah A, et al. (2010). Low HDLCholesterol with Normal Triglyceride Levels is the Most Common Lipid Pattern in West Africans and African Americans with Metabolic Syndrome: Implications for Cardiovascular Disease Prevention. CVD Prev Control 5: 75-80. [Crossref]

38. Delisle H, Ntandou G, Sodjinou R, Couillard C, Despres JP (2013). At-risk serum cholesterol profile at both ends of the nutrition spectrum in West African adults? The Benin study. Nutrients 5: 1366-83. 
Mabchour AEL (2015) Abdominal obesity and other cardiometabolic risk biomarkers in two urban population groups with a common African heritage: Cotonou (Benin) and Port-au-Prince (Haiti)

39. Brunzell JD, Davidson M, Furberg CD, Goldberg RB, Howard BV, et al. (2008). Lipoprotein management in patients with cardiometabolic risk: consensus statement from the American Diabetes Association and the American College of Cardiology Foundation. Diabetes Care 31: 811-22. [Crossref]

40. Kearney PM, Whelton M, Reynolds K, Muntner P, Whelton PK, et al. (2005) Global burden of hypertension: analysis of worldwide data. Lancet 365: 217-223. [Crossref]

41. Foy CG, Hsu FC, Haffner SM, Norris JM, Rotter JI, et al. (2008) Visceral fat and prevalence of hypertension among African Americans and Hispanic Americans: findings from the IRAS family study. Am J Hypertens 21: 910-916. [Crossref]

42. Ostchega Y, Hughes JP, Terry A, Fakhouri TH, Miller I (2012) Abdominal obesity, body mass index, and hypertension in US adults: NHANES 2007-2010. Am J Hypertens 25: 1271-1278. [Crossref]

43. Swan HJ (1999) The Framingham Offspring Study: a commentary. 1980. J Am Coll Cardiol 33: 1136-1140. [Crossref]

44. Okosun IS, Choi S, Hash R, Dever GE (2001) Apolipoprotein B, ratio of total cholestero to HDL-C, and blood pressure in abdominally obese white and black American women. J Hum Hypertens 15: 299-305. [Crossref]

45. Ridker PM, Buring JE, Cook NR, Rifai N (2003) C-reactive protein, the metabolic syndrome, and risk of incident cardiovascular events: an 8-year follow-up of 14719 initially healthy American women. Circulation 107: 391-397. [Crossref]

46. Fuentes E, Fuentes F, Vilahur G, Badimon L, Palomo I (2013) Mechanisms of chronic state of inflammation as mediators that link obese adipose tissue and metabolic syndrome. Mediators Inflamm 2013: 136584. [Crossref]
47. Lumeng CN, Saltiel AR (2011) Inflammatory links between obesity and metabolic disease. J Clin Invest 121: 2111-2117. [Crossref]

48. Ford ES, Giles WH, Mokdad AH, Myers GL (2004) Distribution and correlates of C-reactive protein concentrations among adult US women. Clin Chem 50: 574-581. [Crossref]

49. Ghandehari H, Le V, Kamal-Bahl S, Bassin SL, Wong ND (2009) Abdominal obesity and the spectrum of global cardiometabolic risks in US adults. Int J Obes (Lond) 33 239-248. [Crossref]

50. El Ati J, Traissac P, Delpeuch F, Aounallah-Skhiri H, Beji C, et al. (2012). Gender obesity inequities are huge but differ greatly according to environment and socioeconomics in a North African setting: a national cross-sectional study in Tunisia. PLoS One 7: e48153. [Crossref]

51. Aitsi-Selmi A, Bell R, Shipley MJ, Marmot MG (2014). Education modifies the association of wealth with obesity in women in middle-income but not low-income countries: an interaction study using seven national datasets, 2005-2010. PLoS One 9: e90403. [Crossref]

52. Cooper RS, Rotimi CN, Kaufman JS, Owoaje EE, Fraser H, et al. (1997) Prevalence of NIDDM among populations of the African diaspora. Diabetes Care 20: 343-348. [Crossref]

53. Doumatey AP, Lashley KS, Huang H, Zhou J, Chen G, et al. (2010) Relationships among obesity, inflammation, and insulin resistance in African Americans and West Africans. Obesity (Silver Spring) 18: 598-603. [Crossref]

Copyright: (C)2015 Mabchour AEL. This is an open-access article distributed under the terms of the Creative Commons Attribution License, which permits unrestricted use, distribution, and reproduction in any medium, provided the original author and source are credited. 